\title{
LONGITUDINALLY ASYMMETRIC TRANSPORT OF NITRIC OXIDE IN THE $E$-REGION*
}

\author{
T. E. CRAVENS and T. L. KILLEEN \\ Space Physics Research Laboratory, Department of Atmospheric and Oceanic Science, \\ The University of Michigan, Ann Arbor, MI 48109, U.S.A.
}

(Received in final form 4 June 1987)

\begin{abstract}
Rocket and satellite studies have demonstrated that nitric oxide (NO) in the thermosphere is almost always more abundant at higher than at lower latitudes. The ultraviolet nitric oxide spectrometer (UVNO) on the Atmosphere Explorer $C(A E-C)$ spacecraft observed longitudinal asymmetries in thermospheric NO with greater abundances existing in the longitudinal sector associated with the magnetic poles of both hemispheres. This asymmetry persists even in geomagnetic coordinates. In this paper, we suggest an explanation for the longitudinal asymmetry, using neutral parcel trajectories calculated from the NCAR thermospheric general circulation model (TGCM). It is evident from a study of these calculated trajectories that certain longitudes are favored for equatorward transport out of the auroral zone in the $E$-region. These favored longitudes are those associated with the magnetic poles, where NO is most abundant.
\end{abstract}

\section{INTRODUCTION}

Rocket and spacecraft studies have demonstrated that nitric oxide (NO) is almost always more abundant at higher than at lower latitudes (e.g. Rusch and Barth, 1975; Gérard and Barth, 1977; Cravens and Stewart, 1978; Cravens et al., 1979, 1985; Gérard et al., 1984; McCoy, 1983a, b; Cleary, 1986; Gérard and Noël, 1986), especially in the auroral regions where concentrations in excess of $10^{8} \mathrm{~cm}^{-3}$ have been measured. Cravens $e t$ al. (1985) presented NO densities vs latitude and altitude derived from NO (1-0) gamma band intensities measured by the ultraviolet nitrix oxide spectrometer, UVNO (Barth et al., 1973) on the Atmosphere Explorer $D(A E-D)$ spacecraft. The observed NO concentrations typically reached a maximum between altitudes of 100 and $110 \mathrm{~km}$, with more NO observed at higher than at lower latitudes. An earlier study using UVNO data from the $A E-C$ spacecraft (Cravens and Stewart, 1978) demonstrated that the NO concentration at both mid- and high-latitudes (and sometimes even at low-latitudes) is positively correlated with the $A_{p}$ index of magnetic activity. Furthermore, Cravens and Stewart (1978) found that the NO abundance at a given geographic or geomagnetic latitude exhibits a longitudinal dependence, with minimum densities near $0^{\circ} \mathrm{E}$ longitude in the Southern Hemisphere and near $60^{\circ} \mathrm{E}$ in the Northern Hemisphere, and with maxima near $-70^{\circ} \mathrm{E}$ longitude in

* Dedicated to ALEX DALGARNO in his sixtieth year in honour of his many important contributions to aeronomy. the North and $160^{\circ} \mathrm{E}$ in the South. The longitudinal asymmetry in geographic coordinates is not unexpected due to the offset of the magnetic poles and the consequent longitudinal asymmetry of auroral precipitation. However, the observed NO longitudinal asymmetry in geomagnetic coordinates does not have such a simple explanation.

Cravens et al. (1979) demonstrated that the large observed latitudinal gradient of NO could not be explained using the current one-dimensional theories of odd nitrogen and they concluded that significant horizontal transport from the auroral regions to lower latitudes was required. Roble and Gary (1979) used a relatively simple horizontal transport model to show that this was possible. More recently, Gérard et al. (1984) calculated zonally averaged NO densities using a two-dimensional odd nitrogen model that includes the meridional transport of $\mathrm{NO}$ and atomic nitrogen by thermospheric winds. This two-dimensional model is able to explain many of the features of the observed NO distribution such as the latitudinal gradients of zonally-averaged NO. However, a model restricted to zonal averages is not able to explain longitudinal asymmetries such as those described in the Cravens and Stewart (1978) study. This latter study concluded that, "... the asymmetry about the magnetic pole has no obvious explanation and is perhaps associated with horizontal transport of NO from the auroral zone by thermospheric winds". The purpose of this paper is to demonstrate, using a three-dimensional, timedependent, numerical model of the thermosphere, that NO can indeed be transported away from the auroral regions in a longitudinally asymmetric manner. 
Theoretical general circulation models for the thermosphere have become increasingly sophisticated over the last several years. The two most advanced models are (1) the National Center for Atmospheric Research (NCAR) thermospheric general circulation model (TGCM) (Dickinson et al., 1981; Roble et al., 1982) and (2) the University College London (UCL) TGCM (Fuller-Rowell and Rees, 1980). Recently wind fields generated by these models have been compared with the global wind measurements made at $F$ region altitudes by instruments on board the Dynamics Explorer 2 (DE 2) spacecraft (e.g. Rees et al., 1983; Hays et al., 1984; Roble et al., 1984; Killeen et al., 1986). Good general agreement between the theoretical predictions and averaged spacecraft measurements has been obtained in these various studies indicating that the TGCMs contain valid descriptions of the most important physical processes that control thermospheric dynamics, at least at $F$-region altitudes.

Killeen and Roble (1984) created a diagnostic package to analyze the output of the NCAR TGCM and Killeen and Roble (1986) have used this package to track the trajectories (in space and time) of individual parcels of neutral gas as they move through the TGCM grid. There are very strong indications in the trajectories described by Killeen and Roble (1986) that there is enhanced equatorward transport of $E$ region gas from the auroral regions at those longitudes associated with the magnetic poles.

In this paper, we will re-examine $E$-region trajectories from the Killeen and Roble (1986) paper and evaluate their significance for the longitudinally asymmetric transport of thermospheric NO. Section 2 is a brief review of the Cravens and Stewart (1978) NO data. Relevant trajectories from the Killeen and Roble (1986) study are then presented in Section 3 and used to explain the observed longitudinal asymmetries in the NO distribution. Section 4 is a brief summary.

\section{DISTRIBUTION OF NITRIC OXIDE IN THE E-REGION}

The zonally-averaged distribution of NO with latitude and altitude will be discussed before considering longitudinal variations. Cravens et al. (1985) presented zonally-averaged NO density profiles derived from NO (1-0) gamma band intensities measured by the UVNO instrument on the Atmosphere Explorer $D$ $(A E-D)$ spacecraft using an averaging and inversion procedure. These measurements were made during the period from late November 1975 through early February 1976 with local time varying from 05:30 to $\sim 10: 00 \mathrm{~h}$; that is, the data are characterized by morn-

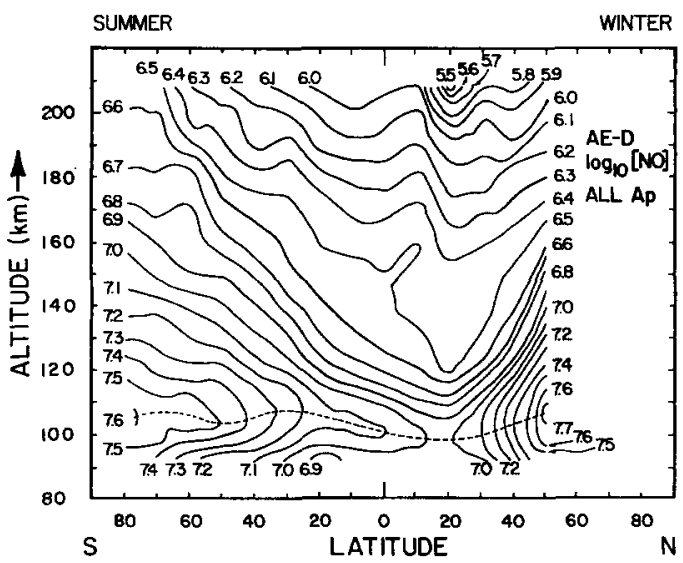

Fig. 1. CONTOUR PLOT OF THE BASE 10 LOG OF THE NITRIC OXIDE NUMBER DENSITY (PER CUBIC CENTIMETER) AS A FUNCTION OF ALTITUdE AND LATITUdE (ADAPTED FROM CRAVENS et al., 1985).

The dashed line indicates the location of the maximum NO concentration as a function of latitude.

ing solstice conditions. Figure 1 is taken from Cravens et al. (1985) and shows contours of NO concentration vs latitude and altitude. Gérard and Noël (1986) have recently published a similar contour plot using magnetic rather than geographic latitude. Several features should be noted in Fig. 1.

The densities of NO at the higher altitudes near $200 \mathrm{~km}$ exhibit a North-to-South gradient with NO being more abundant in the Southern than in the Northern Hemisphere. The NO concentration at these altitudes can be explained in terms of local composition and temperature (Cravens, 1981). The maximum of the NO distribution is located between 100 and $110 \mathrm{~km}$, and the maximum density has a latitudinal minimum near $20^{\circ} \mathrm{N}$ with a sharp gradient towards the North (winter) and a relatively gradual gradient towards the South (summer). Furthermore, the width of the NO peak is broader in the winter hemisphere than in the summer hemisphere.

We next review the theory of NO pertinent to this data set. Nitric oxide in the $100-150 \mathrm{~km}$ region is primarily produced by the reaction of metastable atomic nitrogen, $\mathrm{N}\left({ }^{2} \mathrm{D}\right)$, with molecular oxygen, and the $N\left({ }^{2} D\right)$ is produced by electron impact (by photoelectrons and/or auroral electrons) (cf. Oran et al., 1975; Gérard et al., 1984). Photodissociation of $\mathrm{N}_{2}$ is another possible source of $\mathrm{N}\left({ }^{2} \mathrm{D}\right)$ (Richards et al., 1981). NO is chemically removed from the thermosphere in two ways: (1) by reaction with atomic nitrogen, $\mathrm{N}\left({ }^{4} \mathrm{~S}\right)+\mathrm{NO} \rightarrow \mathrm{N}_{2}+\mathrm{O}$ [this is the major sink of $\mathrm{N}\left({ }^{4} \mathrm{~S}\right)$ ], and (2) by photodissociation, $\mathrm{NO}+\mathrm{h} v \rightarrow$ $\mathrm{N}+\mathrm{O}$. NO has a long lifetime, of the order of 1 day, in the lower thermosphere (Oran et al., 1975), and is 
especially long-lived at higher latitudes where it is most abundant. This latter feature of NO chemistry arises from the fact that $\mathrm{NO}$ and $\mathrm{N}\left({ }^{4} \mathrm{~S}\right)$ destroy each other so that where NO becomes abundant [due, for example, to auroral enhancements in $\left.\mathrm{N}\left({ }^{2} \mathrm{D}\right)\right] \mathrm{N}\left({ }^{4} \mathrm{~S}\right)$ consequently becomes scarce, leading in turn to a reduction in the loss rate for NO. In addition to this chemical feedback, a further consideration becomes important at high latitudes. In the polar winter night NO cannot be lost by photodissociation and, therefore, in the absence of both of its loss mechanisms, the NO density can build up to extremely high values. The long chemical lifetime means that NO in the lower thermosphere can be transported appreciable distances, in either the vertical or horizontal directions, especially at higher latitudes. Most NO in the lower thermosphere diffuses downward (via both molecular and eddy diffusion) from where it is created between 100 and $150 \mathrm{~km}$, through the $100-110 \mathrm{~km}$ region (where the distribution reaches a maximum) and into the mesosphere, or even into the upper stratosphere in the polar night region (see Solomon and Garcia, 1984, and references therein). Furthermore, strong equatorward thermospheric winds can remove NO from the auroral region and transport it towards the equator (Gérard et al., 1984). The two-dimensional model of Gérard et al. (1984) can reproduce the most important features of the zonally-averaged data shown in Fig. 1.

We next review the previously unexplained longitudinal variations of NO in the lower thermosphere. Figure 2 is a reproduction of the two polar maps of NO distributions from Cravens and Stewart (1978). The reader is referred to this article for details concerning the maps, although we discuss the germane features here. The contours shown are for instrumental counts registered by the UVNO instrument on the $A E-C$ spacecraft for a tangential ray height of 105 $\mathrm{km}$; the NO densities at $105 \mathrm{~km}$ which approximately correspond to the instrumental counts are also indicated in the figure. Note that there are no data within about $22^{\circ}$ of the geographic poles due to the inclination of the $A E-C$ orbit. Figure 2a includes data for the Northern Hemisphere and for days 21-45 of 1974 (basically winter solstice) with an average $A_{p}$ of 20 . Figure $2 \mathrm{~b}$ includes data for the Southern Hemisphere and for days 212-249 (conditions between winter solstice and equinox but closer to equinox). The average $A_{p}$ is 23 for this data set. Two significant trends are evident in Fig. 2: (1) NO is more abundant at higher latitudes and the maximum appears to be located between $60^{\circ}$ and $70^{\circ}$ latitude, although this is difficult to determine unambiguously due to the data gap, and (2) NO is most abundant at those longitudes associated with the geomagnetic pole for the particular hemisphere in question and this longitudinal asymmetry persists when magnetic coordinates are used, at least in the Southern Hemisphere and in the summer. For instance, the 1000 count contour in Fig. $2 \mathrm{~b}$ (Southern Hemisphere) extends well beyond the $50^{\circ} \mathrm{S}$ geomagnetic latitude circle in the "favored" longitudinal sector (i.e. the sector containing the south geomagnetic pole). However, the asymmetry for the Northern Hemisphere data set is not so pronounced. The 1000 count contour in Fig. 2a is approximately concentric with the $50^{\circ} \mathrm{N}$ geomagnetic latitude circle, although there is still a slight "shift" towards the favored longitudes. A northern summer/equinox data set in the Cravens and Stewart (1978) study (their Fig. 3 not reproduced here) shows the longitudinal asymmetry in both geographic and geomagnetic coordinates clearly. The implication is that the longitudinal asymmetry is more pronounced in the summer and/or the Southern Hemisphere. Furthermore, the latitudinal gradient appears to be steeper in the winter and more gradual in the summer. For example, the contours in Fig. 2b (not summer but closer to it than in Fig. 2a) are further apart than in Fig. 2a (winter).

\section{NEUTRAL PARCEL TRAJECTORIES FROM THE NCAR TGCM}

The NCAR TGCM is a three-dimensional, timedependent model of the Earth's neutral upper atmosphere that runs on the CRAY-1 computer at the National Center for Atmospheric Research. The full, coupled, nonlinear, hydrodynamic, thermodynamic and continuity equations of the neutral gas are solved on a three-dimensional grid using a finite differencing scheme to step forward in space and time. The horizontal grid size is $5^{\circ}$ in both latitude and longitude and there are 24 pressure surfaces in the vertical from approximately 97 to $500 \mathrm{~km}$. The magnetospheric convection model of Sojka et al. (1979) including displaced geomagnetic poles (North geomagnetic pole: $78.3^{\circ} \mathrm{N}$ latitude and $291.0^{\circ} \mathrm{E}$ longitude, and South geomagnetic pole : $74.5^{\circ} \mathrm{S}$ latitude and $127.0^{\circ} \mathrm{E}$ longitude) is used for the specification of the ion drift velocity field. The neutral gas gains or loses momentum from or to the ions via ion-neutral drag and tends to mimick the two-cell circulation pattern of the polar ionospheric/magnetospheric circulation, albeit with time lags etc. The heating and conductivity enhancements due to particle precipitation in the auroral oval are also included in the model description. Dickinson et al. (1981) and Roble et al. (1982, 1983, 1984) have described the model and the reader is referred to these articles for details. Roble et al. (1983) used the TGCM 

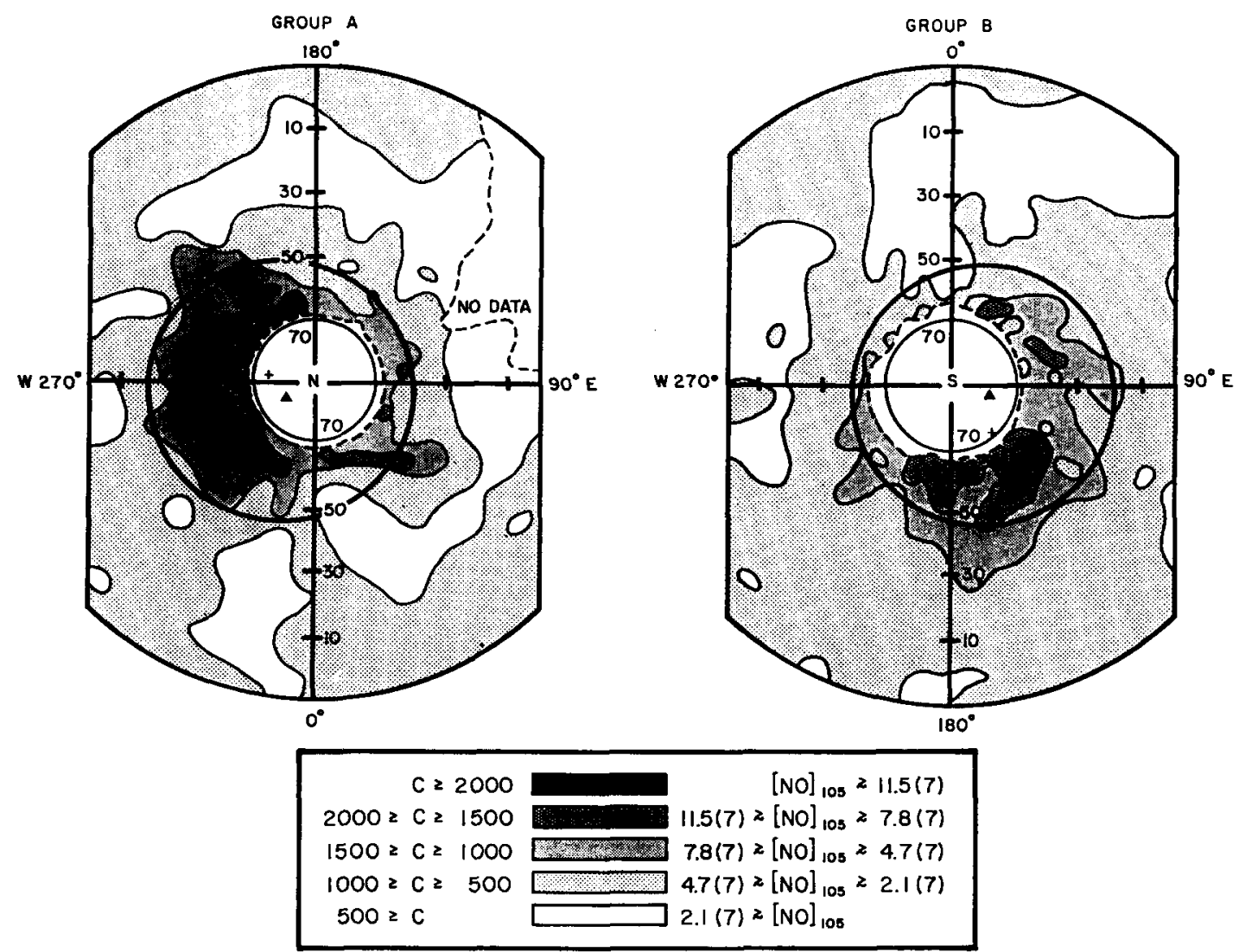

Fig. 2. Maps in polar coOrdinates SHOWing (a) THE Northern Hemisphere and (b) the Southern HEMISPHERE MEASUREMENTS FROM GROUPED ORBITS (ADAPTED FROM CRAVENS AND STEWART, 1978).

The $70^{\circ}$ geographic parallel is shown, as is the $50^{\circ} \mathrm{S}(\mathrm{N})$ geomagnetic parallel. The South (North) geomagnetic and dip poles are indicated by the triangle and the cross, respectively.

to investigate the influence of magnetospheric convection on the high-latitude neutral circulation and temperature structure and Killeen et al. (1986) have recently used output from the TGCM to compare with extensive $F$-region wind measurements from ground and space.

Killeen and Roble (1984) developed a diagnostic package to study the output of the TGCM and analyzed the terms in the basic equations describing different physical processes. This package also traces the trajectories of individual neutral gas parcels, and this is just what is needed in order to follow the transport of long-lived species such as NO. In this section we will review the $E$-region ( $z=-4$ constant-pressure surface near $120 \mathrm{~km}$ ) trajectories presented in Killeen and Roble (1986), since this is the altitude region relevant to odd nitrogen in the lower thermosphere. Figure 3 is adapted from Fig. 5 of their paper and shows three representative parcels for the Southern Hemisphere, calculated using geophysical input conditions appropriate for 21 October 1981 (midway between the equinox and summer solstice). Wind fields at several Universal Times (U.T.s) are also shown to illustrate the global-scale circulation pattern within which the individual parcels move. The wind vectors are plotted with respect to the corotating Earth, as discussed by Killeen and Roble. The geophysical inputs for the specific model run are also discussed in the Killeen and Roble (1986) paper and include a steady cross-polar cap potential of $60 \mathrm{kV}$ and steady auroral forcings corresponding to a $K_{p}$ of 3-4. The geomagnetic inputs are held steady over the $24 \mathrm{~h}$ period of the model run, producing the basic "diurnally-reproducible" wind field which has been shown to resemble averaged $D E-2$ measurements at $F$-region altitudes (Hays et al., 1984; Roble et al., 

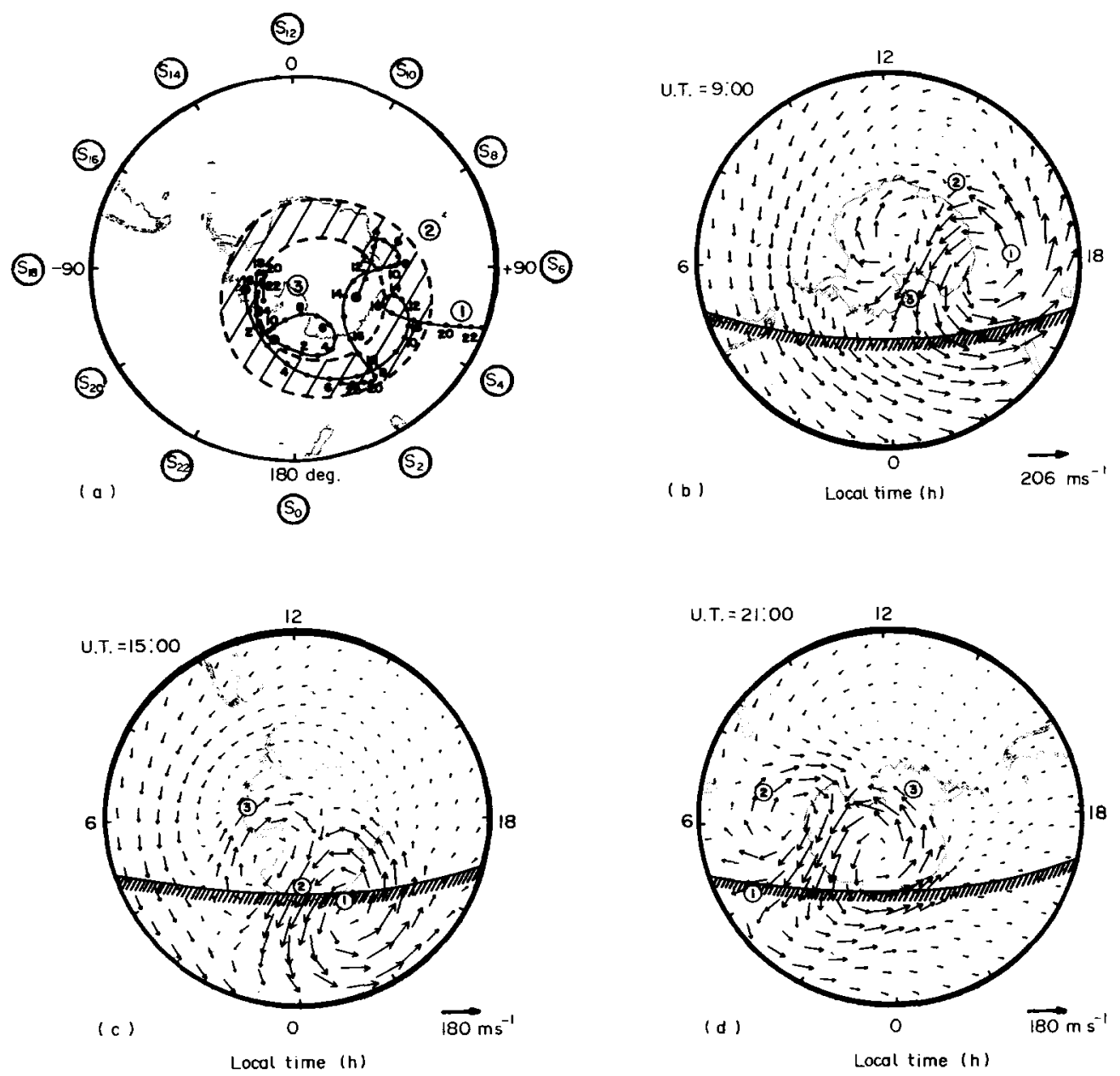

Fig. 3. Polar dials for the Southern Hemisphere (POle to - $40^{\circ}$ latitude) illustrating the locus OF THREE NEUTRAL PARCEL TRAJECTORIES CALCULATEd USING THE NCAR TGCM FOR A DIURNALLYREPRODUCIBLE MODEL RUN FOR 21 OCTOBER 1981.

The trajectories are for the $z=-4(\sim 120 \mathrm{~km})$ constant pressure surface. (a) Plot in geographic coordinates (latitude and longitude) showing the loci for the three parcels. The numbers on the loci refer to hours of Universal Time. The circled symbols on the periphery of the plot indicate the direction towards the Sun at the U.T. indicated by the subscript. The approximate location of the auroral oval is indicated by the hatched area, (b), (c) and (d) illustrate the locations for the individual parcels at 09:00, 15:00 and 21:00 $\mathrm{h}$ U.T., respectively, together with the TGCM-calculated neutral wind field (wind scale at lower right). The wind fields in (b), (c) and (d) are plotted with respect to the rotating Earth-i.e. winds as would be observed from the ground. The polar plots are in geographic latitude and local solar time coordinates and the solar terminator is indicated by the curved line. This figure is an adaptation of Fig. 5 of Killeen and Roble (1986).

1984). The approximate location of the auroral oval is indicated in Fig. 3a by the cross-hatching.

Two characteristics are required for a given trajectory if it is to imply significant transport of NO from the auroral region to lower latitudes. These are: (1) the residence time of the parcel in the auroral oval must be relatively long (many hours) in order to give the particle precipitation production of $N\left({ }^{2} D\right)$ a chance to build up the NO abundance, and (2) the parcel must reach latitudes significantly equatorward of the auroral region, and do this in a reasonably short time (i.e. about $24 \mathrm{~h}$, a typical lifetime for $\mathrm{NO}$ at mid-latitudes in the sunlight). For such equatorward transport of NO to have a systematic bias towards a given longitude sector, a parcel with the above two characteristics must be somehow preferentially "pumped" out of the high-latitude region in the specific sector. We propose to show that parcels of $E$-region 
gas which both dwell in the auroral oval for appreciable periods and are transported by thermospheric winds to lower latitudes do indeed have a natural preference for the longitude sector containing the geomagnetic pole. Furthermore, the trajectory analysis provides a simple explanation for the observations that have shown that NO longitudinal asymmetries are more pronounced in the Southern Hemisphere than in the Northern Hemisphere and in the summer than in the winter.

Consider the parcel labelled 1 in Figs $3 a-d$. This parcel starts at 00:00 U.T. in the auroral oval and remains in the oval until 18:00 U.T.- that is, the residence time is very long, $\sim 18 \mathrm{~h}$. At about 16:00 U.T., the parcel undergoes an equatorward surge, crosses the oval, and continues down to mid-latitudes by about 23:00 U.T. Notice that the longitude where this burst of meridional transport takes place is $110^{\circ} \mathrm{E}$-in the same longitudinal sector as the South geomagnetic pole, which is where NO has an enhanced concentration. The two other parcels, labelled 2 and 3 , which start in different locations (approximately polar cap), meander in and out of the auroral oval and never make it out of the oval/polar cap region (at least not in the $24 \mathrm{~h}$ period considered here). These three parcels are just representative examples of a much larger number (hundreds) of parcels that have been followed for this diurnally-reproducible, summer, Southern Hemisphere simulation; all have the characteristic that those that escape to lower latitudes do so only in the favored longitude sector.

In order to understand why the equatorward "escape" of parcels occurs at favored longitudes, one must examine the wind fields shown in Figs $3 b-d$ for several U.T.s. We note first that, as discussed by Killeen and Roble (1986), the $E$-region wind velocities (plotted here with respect to the rotating Earth) are, in general, smaller in magnitude than the velocity of corotation and that, therefore, the parcels on the L.T./latitude plots (Figs $3 b-d$ ) follow principally clockwise (corotational) trajectories modified by the magnetospherically-driven twin-cell wind pattern shown. Let us look more closely at the trajectory of parcel 1 . At 03:00 U.T. this parcel resides in the region of sunward neutral flow associated with the dusk cell of the circulation pattern. This sunward velocity is largely cancelled by the oppositely-directed velocity of corotation and the parcel drifts out of the region of strong sunward flow and to slightly lower latitudes where corotation is even more dominant (Fig. 3b). The parcel continues to corrotate until, near 15:00 U.T. (Fig. 3c) it enters the region of maximum antisunward neutral wind associated with the central region of the twin-cell ion convection pattern. It is in the U.T. period 15:00-21:00 $\mathrm{h}$ that parcel 1 obtains the meridional (equatorward) momentum that is sufficient to eject the parcel from the high-latitude region. Of significance is the fact that the insertion of meridional momentum for parcel 1 occurs just in the U.T. period when the twin-cell circulation pattern is at its maximum displacement towards midnight (or, equivalently, when the geomagnetic pole is maximally offset from the geographic pole in the antisunward direction). Thus, parcel 1 acquires equatorward momentum in a region that is already biased to lower latitudes and this burst of momentum is sufficient to allow the parcel to escape from high-latitudes. Other parcels that enter the anti-solar jet (such as parcels 2 and 3) do so at times when the meridional velocity imparted is insufficient to overcome the combined effects of corrotation and sunward forcing associated with the dawn sunward ion convection. These latter effects tend to sweep the parcel back towards highlatitudes and once more into the twin-cell circulation pattern as discussed by Killeen and Roble (1986).

Now let us consider some Northern Hemisphere parcel trajectories, also for 21 October (and therefore equinox/winter solstice conditions). These are shown in Fig. 4 which is adapted from Killeen and Roble (1986). Notice that almost the whole circulation pattern is in darkness which means that the neutral wind velocities are much lower because the night-time ionospheric densities are low and ion-neutral drag is therefore much weaker. The pattern is rotated by about $90^{\circ}$ due to the increased importance of neutral inertia relative to drag. Because of the reduced wind speeds when compared with the summer case, one might suppose that equatorward transport would be weaker, regardless of the longitude. Indeed, none of the three representative parcels shown here have both of the characteristics (discussed above) necessary for significant equatorward transport of NO. Parcel 1 meanders back and forth across the polar cap; parcel 2 does linger in the auroral oval but only makes it to the southern edge of the oval (this at least is promising). Parcel 3 never resides in the oval at all, but does have some slight equatorward transport. Clearly, in the quiet-time winter polar $E$-region modelled here there is less net equatorward transport of neutral parcels than in the summer. Furthermore, in the absence of such transport, the only NO loss mechanism for the winter polar night $E$-region (where photodissociation does not occur) is via downward diffusion, as discussed by Solomon et al. (1982).

We note here that, at geomagnetically active times, the winter circulation pattern becomes much more like the summer pattern shown in Fig. 3 due to the enhanced conductivities and ion-drag forces associ- 

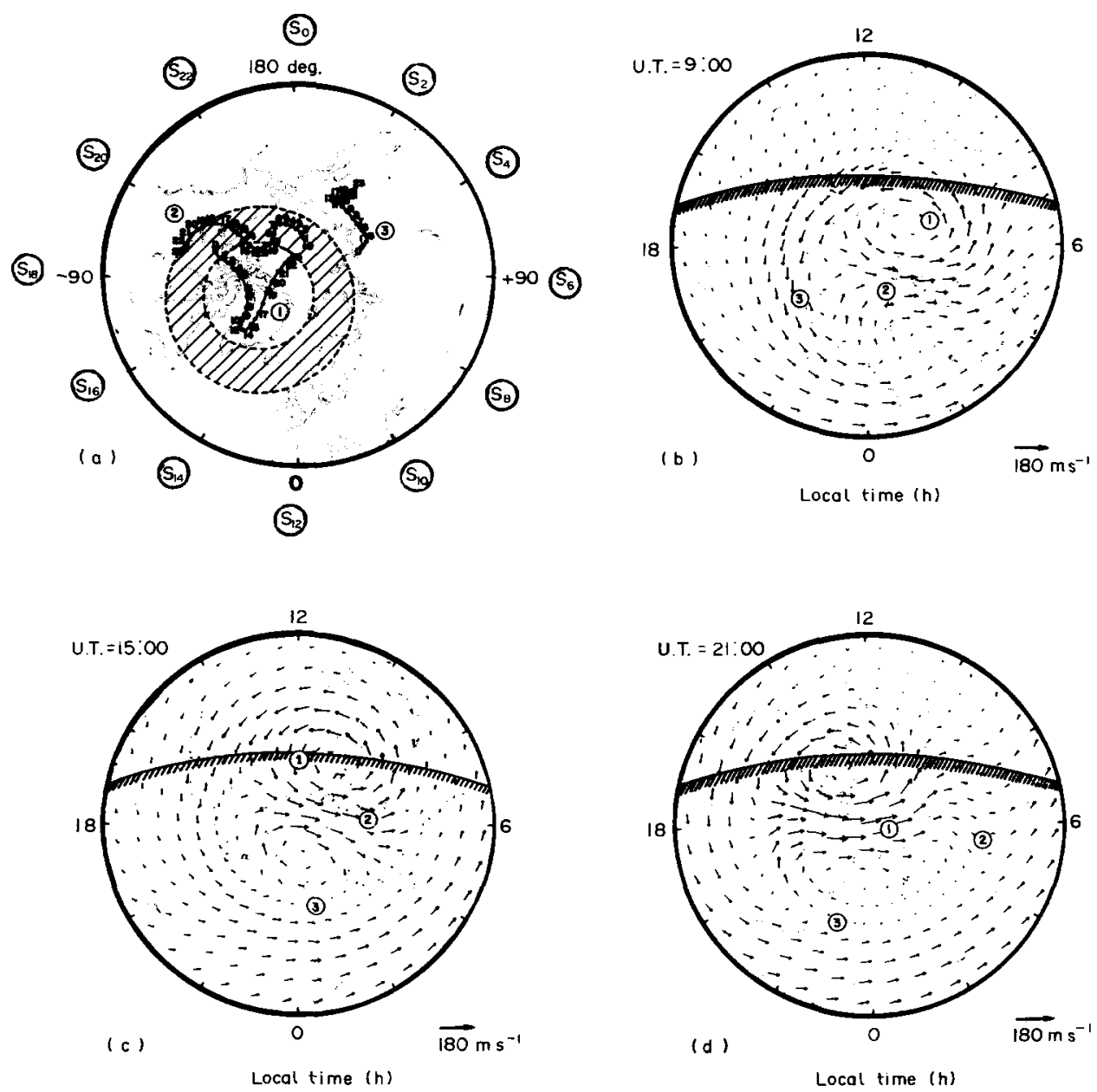

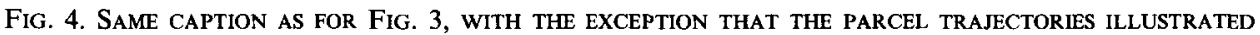
ARE FOR THE NORTHERN HEMISPHERE.

ated with the greater degree of magnetospheric forcing of the thermosphere. Thus a similar longitude preference for NO equatorward transport might be expected in the winter hemisphere for geomagnetically active conditions. The longitudinal asymmetry in the Northern Hemisphere would, however, be expected to be weaker than in the Southern Hemisphere for the same geomagnetic/seasonal conditions in part because the equatorward displacement of the circulation pattern in the Northern Hemisphere is smaller than for the Summer Hemisphere due to the smaller separation of the geographic and geomagnetic poles in the North than in the South.

We also note that even for the most significant case of $E$-region parcel transport presented here (parcel 1 of Fig. 3), the meridional wind speed is not large and most NO contained in the parcel would be photodissociated long before reaching equatorial latitudes. Thus the occurrence of significant quantities of NO observed at low latitudes by the Solar Mesosphere Explorer spacecraft (Barth, 1986) is considered to be due to either considerably enhanced (stormtime) meridional transport or to in situ production (perhaps aided by neutral temperature enhancements, R. G. Roble, 1985, private communication). A full three-dimensional chemical/dynamical model of NO production and transport will be necessary to explain fully such global distributions. The high-latitude tails of NO reported from the Atmosphere Explorer data, however, are qualitatively explained by the diurnally- 
reproducible parcel trajectory calculations presented here.

\section{SUMMARY}

A consideration of previously published neutral parcel trajectory calculations made using the NCAR TGCM provides a qualitative explanation for the summer/winter and longitudinal asymmetries in the high-latitude NO concentrations reported by Cravens and Stewart (1978). In particular the longitudinal asymmetries that show significant "tails" of NO at the longitudes of the geomagnetic pole in either hemisphere can be explained in terms of direct neutral parcel transport from the auroral oval. Parcels at the favored longitudes are subject to equatorward forcing by the anti-sunward convecting ions in the central region of the ionospheric convection pattern at the time that the pattern is displaced maximally in the equatorward direction. The combination of the geometrical alignment of the convection pattern and the magnitude of the anti-solar winds provides sufficient meridional momentum for such parcels to escape the high-latitude region. Other parcels are successively drawn back into the high-latitude region and do not acquire the "escape velocity".

In addition to the natural longitude selection for NO equatorward transport reported here, the TGCM calculations indicate that such transport will be more important for summer than for winter conditions due to the higher wind speeds.

While providing a simple and intuitive explanation for previously reported NO concentration asymmetries, the present work points to the need for a comprehensive three-dimensional chemical/ dynamical model to describe fully the morphology of thermospheric NO.

Acknowledgements - The work was supported in part by NSF grant numbers ATM-8412828, ATM-8610085 and ATM-8508753 to the University of Michigan. One of the authors (TLK) is grateful to Dr R. G. Roble of the High Altitude Observatory at the National Center for Atmospheric Research for providing access to the NCAR TGCM and for numerous stimulating discussions.

\section{REFERENCES}

Barth, C. A. (1986) Thermospheric nitric oxide. Trans. Am. Geophys. Union 67, 1126.

Barth, C. A., Rusch, D. W. and Stewart, A. I. (1973) The UV nitric oxide experiment for Atmosphere Explorer. Radio Sci. 8, 379.

Cleary, D. D. (1986) Daytime high-latitude rocket observations of the NO $\gamma, \delta$ and $\varepsilon$ bands. J. geophys. Res. 91, 11337.

Cravens, T. E. (1981) The global distribution of nitric oxide at $200 \mathrm{~km}$. J. geophys. Res. 86, 5710 .
Cravens, T. E., Gérard, J.-C., LeCompte, M., Stewart, A. I. and Rusch, D. W. (1985) The global distribution of nitric oxide in the thermosphere as determined by the Atmosphere Explorer D satellite. J. geophys. Res. 90, 9862.

Cravens, T. E., Gérard, J.-C., Stewart, A. I. and Rusch, D. W. (1979) The latitudinal gradient of nitric oxide in the lower thermosphere. J. geophys. Res. 84, 2675.

Cravens, T. E. and Stewart, A. I. (1978) Global morphology of nitric oxide in the lower E-region. J. geophys. Res. 83, 2446.

Dickinson, R. E., Ridley, E. C. and Roble, R. G. (1981) A three-dimensional general circulation model of the thermosphere. J. geophys. Res. 86, 1499.

Fuller-Rowell, T. J. and Rees, D. (1980) A three-dimensional, time dependent global model of the thermosphere. J. atmos. Sci. 37, 2545.

Gérard, J.-C. and Barth, C. A. (1977) High latitude nitric oxide in the lower thermosphere. J. geophys. Res. 82, 674.

Gérard, J.-C. and Noël, C. E. (1986) $A E-D$ measurements of the NO geomagnetic latitudinal distribution and contamination by $\mathrm{N}^{+}$(5S) emission. J. geophys. Res. 91, 10136.

Gérard, J.-C., Roble, R. G., Rusch, D. W. and Stewart, A. I. (1984) The global distribution of thermospheric odd nitrogen for solstice conditions during solar cycle minimum. J. geophys. Res. 89, 1725.

Hays, P. B., Killeen, T. L., Spencer, N. W., Wharton, L. E., Roble, R. G., Emery, B. A., Fuller-Rowell, T. J., Rees, D., Frank, L. A. and Craven, J. D. (1984) Observations of the dynamics of the polar thermosphere. $J$. geophys. Res. 89, 5597.

Killeen, T. L. and Roble, R. G. (1984) An analysis of the high-latitude thermospheric wind pattern calculated by a thermospheric general circulation model, 1, Momentum forcing. J. geophys. Res. 89, 7509.

Killeen, T. L. and Roble, R. G. (1986) An analysis of the high-latitude thermospheric wind pattern calculated by a thermospheric general circulation model, 2, Neutral parcel transport. J. geophys, Res. 91, 11291.

Killeen, T. L., Roble, R. G., Smith, R. W., Spencer, N. W., Meriwether, J. W., Rees, D., Hernandez, G., Hays, P. B., Cogger, L. L., Sipler, D. P., Biondi, M. A. and Tepley, C. A. (1986) Mean neutral circulation in the winter polar $F$ region. J. geophys. Res. 91, 1633.

McCoy, R. P. (1983a) Thermospheric odd nitrogen, 1, NO, $N\left({ }^{4} \mathrm{~S}\right)$, and $O\left({ }^{3} \mathrm{P}\right)$ densities from rocket measurements of the NO $\delta$ and $\gamma$ bands and the $\mathrm{O}_{2}$ Herzberg I bands. $J$. geophys. Res. 88, 3197.

MCoy, R. P. (1983b) Thermospheric odd nitrogen, 2, Comparison of rocket observations with a diffusive transport chemical model. J. geophys. Res. 88, 3206.

Oran, E. S., Julienne, P. S. and Strobel, D. F. (1975) The aeronomy of odd nitrogen in the thermosphere. J. geophys. Res. 80, 3068.

Rees, D., Fuller-Rowell, T. J., Gordon, R., Killeen, T. L., Hays, P. B., Wharton, L. E. and Spencer, N. W. (1983) A comparison of thermospheric wind observations with the predictions of a global time-dependent model. Planet. Space Sci. 31, 1299.

Richards, P. G., Torr, D. G. and Torr, M. R. (1981) Photodissociation of $\mathrm{N}_{2}$ : a significant source of the thermospheric atomic nitrogen. J. geophys. Res. 86, 1495.

Roble, R. G., Dickinson, R. E. and Ridley, E. C. (1982) Global circulation and temperature structure of thermosphere with high-latitude plasma convection. $J$. geophys. Res. 87, 1599. 
Roble, R. G., Dickinson, R. E., Ridley, E. C., Emery, B. A., Hays, P. B., Killeen, T. L. and Spencer, N. W. (1983) The high latitude circulation and temperature structure of the thermosphere near solstice. Planet. Space Sci. 31 1299.

Roble, R. G., Emery, B. A., Dickinson, R. E., Ridley, E. C., Killeen, T. L., Hays, P. B., Carignan, G. R. and Spencer, N. W. (1984) Thermospheric circulation, temperature, and compositional structure of the southern hemisphere polar cap during October-November, 1981. J.geophys. Res, 89, 9057.

Roble, R. G. and Gary, J. M. (1979) The effect of horizontal transport on auroral NO densities. Geophys. Res. Lett. 6 , 703.
Rusch, D. W. and Barth, C. A. (1975) Satellite measurements of nitric oxide in the polar region. $J$. geophys. Res. 80, 3719.

Sojka, J. J., Raitt, W. J. and Schunk, R. W. (1979) Effect of displaced geomagnetic and geographic poles on the highlatitude plasma convection and ionospheric depletions. $J$ geophys. Res. 84, 5943.

Solomon, S., Crutzen, P. J. and Roble, R. G. (1982) Photochemical coupling between the thermosphere and the lower atmosphere, 1 , Odd nitrogen from 50 to $120 \mathrm{~km}$. $J$. geophys. Res. 87, 7206.

Solomon, S. and Garcia, R. R. (1984) Transport of thermospheric NO to the upper stratosphere? Planet. Space Sci. 32, 399. 